Article

\title{
A Method of Evaluating Ecological Compensation Under Different Property Rights and Stages: A Case Study of the Xiaoqing River Basin, China
}

\author{
Yuheng Yang, Xi Zhang, Leran Chang, Yufei Cheng and Shengle Cao * \\ College of Civil Engineering, Shandong University, Jinan 250061, Shandong, China; \\ jinle@cau.edu.cn (Y.Y.); 1109080115@cau.edu.cn (X.Z.); \\ 201513402@mail.sdu.edu.cn (L.C.); 201613335@mail.sdu.edu.cn (Y.C.) \\ * Correspondence: cao_s@sdu.edu.cn
}

Received: 1 January 2018; Accepted: 18 February 2018; Published: 27 February 2018

\begin{abstract}
To solve the problem of unitary ecological compensation standards in river basins by scientifically clarifying the compensation for ecological protection investments and for pollution, this research divided ecological environment property relations between the upstream and downstream into three types: downstream ecological compensation for the upstream, upstream ecological compensation for the downstream and sharing the rights of the ecological environment. The various compensation standards were divided into three stages according to the location quotient and pollutant concentration. Calculation and analysis were performed for the ecological compensation of the Xiaoqing River Basin at the junction of Jinan City and Binzhou City of Shandong Province as an example. The results showed that: (1) the downstream compensations for the three stages were 2.139 billion yuan, 2.349 billion yuan and 2.489 billion yuan when only the downstream ecological compensation for the upstream was considered; (2) the compensations for the three stages were 88 million yuan, 107 million yuan, 124 million yuan when only the upstream ecological compensation for the downstream was considered; and (3) the compensations in the three stages were 2.051 billion yuan, 2.242 billion yuan, 2.365 billion yuan when ecological environment rights were shared. Under this property relation, the ecological compensation standard considering water quality and water yield and the goal of ecological environmental protection are clear and the content of compensation is complete, which is easily accepted by all parties.
\end{abstract}

Keywords: ecological environment property relation; ecological compensation; location quotient; pollutant concentration; Xiaoqing River Basin

\section{Introduction}

Natural resources and ecological environments are basic needs for the existence and development of humanity [1,2]. Since most ecosystem services are for public goods or quasi-public goods, they cannot enter the market. The opinion that ecosystem services have no value has been ingrained in the minds of people for a long time and has permeated all aspects of economic and social activities. According to estimates from the United Nations Millennium Ecosystem Assessment [3], during 1960-2005 there was a huge demand for ecosystem services, with a doubling of world population and a growth rate more than six times that of the global economy, whereas nearly $2 / 3$ of the ability of ecosystem services declined. This shows that the improvements from industrialization came at the expense of the accelerated consumption of natural assets and that human beings must explore ways to solve ecological environmental problems [4].

Ecological compensation is an important economic means to protect ecosystem services and regulate market failure for the protection and sustainable use of the ecosystem $[5,6]$; 
ecological compensation takes economic means as the main way to adjust the institutional arrangement of stakeholder interests [7]. Specifically, ecological compensation includes the four following main aspects: (1) the cost to protect the ecosystem itself; (2) externality of economic benefits should be internalized by economic means; (3) economic compensation to individuals or regional protection of ecosystems and environments for the loss of development opportunities; and (4) protective actions undertaken for regions or objects with great ecological value [8].

Ecological compensation mechanisms could encourage local governments, environmental NGOs and community groups to seek new means to protect water resources, which will promote the economic growth of poor rural areas during ecological protection. With increasing demand for water resources from ecological compensation systems, the topic of water ecological compensation began to appear as an object of study [9-11]. At present, foreign experts and scholars in the field of watershed ecological compensation standards say that such standards are generally based on ecological environment construction and protection costs, ecosystem services values or willingness to pay the values of ecological services and other aspects of measurement. Pagiola [12] interpreted the basic idea of the theoretical framework of ecological compensation and proposed the idea of ecological compensation quota calculation based on the ecological value equivalent from the perspective of geographic scale correlation and scale conversion. Pimentel [13] used the ecosystem value equivalent method to estimate the service value of natural capital and calculated the benefits directly or indirectly obtained from the ecosystem. Kong [14] used the willingness to pay (WTP) value evaluation method, taking the Poyang Lake wetland as an example, and determined watershed ecological service values and the corresponding ecological compensation standard. However, the definition of the ecological environmental property rights of these studies is vague, and the cost and income of the damaged party or beneficiary party are often considered. The determined ecological compensation standards often find it difficult to consider the interests of all parties. At the same time, the ecological compensation is not sufficiently humane and the amount of compensation is too small. Single compensation standards often lead to the phenomena of excessive compensation and insufficient compensation, which leads to difficulty implementing compensation policy $[15,16]$.

In China, water resources mainly belong to the state and collective ownership; therefore, water resources and ecosystem services are not implemented by market transactions but through financial transfer payments for ecosystem services provider compensation by the central or local government [17]. In recent years, many provinces and municipalities have carried out some policy tests related to the ecological compensation of water resources [18,19], and state ministries and commissions, such as the Ministry of Environmental Protection, the National Development and Reform Commission (NDRC), the Finance Bureau, and the Forestry Bureau, have begun to study the issue of ecological compensation mechanisms [20]. In 2017, the 19th Session of National Congress of the Communist Party of China clearly proposed to vigorously promote the construction of ecological civilization [21], implement important ecological system protection and rehabilitation for major projects, and establish market-oriented, diversified ecological compensation mechanisms. Based on this, ecological compensation will become an important means of water resources utilization and will benefit the balance of water environment utilization in the new period in China.

Based on the preceding developments, we will redefine the ecological environment of a river basin property, consider the location quotient and pollutant concentrations, and propose a multi-stage standard of ecological compensation between downstream watersheds, with ecological compensation of the local governments in Xiaoqing River basin as an example, to calculate the compensation standard for different ecological environment property relations and different stages under the standard to draw relevant conclusions and policy implications. This work can provide theoretical scientific guidance for the calculation of watershed ecological compensation standards. 


\section{Methodology}

We defined the main body of valley ecological compensation in this study as the upstream and downstream of a river basin and the compensation object as the maintenance of ecological function, the investment of ecological function protection, and the loss caused by the ecological environment utilization of the river basin. To determine the scope and standard of compensation, we first needed to determine the goal of ecological and environmental protection and governance for each subject of compensation, which is determined by national and local ecological environmental management departments according to the ecological environmental protection target area, environmental capacity and regional social and economic development goals. Then, based on the definition of the ecological property rights of the participants, ecological compensation can comprehensively compensate for the ecological protection investment and pollution damage [22,23].

We assume that the ecological construction and protection of investments will be carried out in the upper catchment; however, because of the public good the ecological environment resources in the basin cannot be exclusively consumed. The ecological and environmental services provided by these inputs have externalities that are shared by the upper and lower consumers of the basin, and the right to ecological services based on investment in ecological protection is thus owned by both the upstream and downstream. However, the pollution rights or emissions rights based on watershed environmental capacity between the upper and lower reaches of the river basin are hard to define, and who owns the environmental capacity in the upper and lower reaches of a river basin will determine the objects of pollution compensation and the standard of compensation. Based on the above definitions of two kinds of river basin ecological environmental rights, we divided property rights for the downstream ecological environments into three cases: the upstream pollution rights, no pollution rights upstream, and the downstream sharing of ecological and environmental rights. Then, we established water allocation and water compensation factors for the consideration of the ecological environment services, different watershed construction property rights and different water quality standards under the downstream ecological compensation standard [24].

\subsection{Downstream Ecological Compensation}

In the ecological construction and protection of investments in an upstream watershed, both the upstream and downstream are the beneficiaries and one needs to assume the service values of the corresponding costs. Different watersheds have their dominant ecosystem services, and reasonable water resources ecological compensation standards should be formulated based on the service values of the dominant water ecosystem in the basin. In this study, we used the group standard of ecosystems defined by Xie Gaodi $[25,26]$ as follows: four categories of services are defined (supply services, regulating services, support services, and cultural services) and for each category 11 functions are defined: food production, raw material production, water supply, gas regulation, climate regulation, purification of the environment, hydrological regulation, soil conservation, nutrient cycling, biodiversity, and aesthetic landscape. The distribution system of water resources ecological conditions, service climate, human activities and other factors is shown in different leading ecosystem services in terms of the area and the time range of different spaces. For example, the water resources ecosystem in some areas is dominated by climate adjustment services, whereas in other areas it may be mainly based on environmental purification services. Additionally, we need to consider the local financial capacity. Therefore, this paper borrows the concept and method of the location quotient [27] to refine and clarify ecological compensation standards of water resources.

\subsubsection{Ecological Location Quotient}

The expression of the ecological location quotient is as follows:

$$
q_{i}=\frac{e_{j} / e}{E_{j} / E}
$$


where $q_{j}$ is an ecological location quotient for the section $j$ of the water resources ecosystem services, $e_{j}$ is a service value of the section $j$ of the water resources ecosystem, $e$ is the total value of water resources ecosystem services for the study area, $E_{j}$ is the service value of the section $j$ of the water resources ecosystem, and $E$ is the total value of the national water resources and ecosystem services.

Section 11 of the service value of the water resources $e_{j}$ was divided into three categories; the smallest one was the first-level dominant water resources ecosystem service in the study area, the second type of ecosystem services was the two-level water resources leading ecosystem service in the study area, and the largest potential water resources ecosystem service in the study area was for studying the potential of the water resources ecological system.

\subsubsection{Downstream Ecological Compensation for the Upstream}

The ecological compensation coefficient $\alpha$ is used to measure the current level of economic development and what standard payment service people are willing to pay. In the growth curve model of Pearl, the dependent variable is used to reflect the change trend of $P$ within a time model $[28,29]$. The model can be briefly described as follows: the growth rate gradually increases from the beginning because of the slow growth of variables and then enters a rapid growth stage followed by a slow decrease in the growth rate; this trend reflects the characteristics of periodic changes of development. The characteristics of the value of ecological environment awareness also reflect a similar dynamic process. In an early stage of development, it is difficult for people to have a full understanding of the value of the ecological environment; however, when the economy develops to a certain stage and the problems of food and clothing are solved, especially after a comfortable standard of living is obtained, the people's demand for environmental services and the degree of attention to the ecological environment will increase and then continue to develop to a high saturation stage [30]. Therefore, we used the Engel coefficient (defined below) and the simplified Pierre growth curve model to represent the level of economic and social development to calculate the ecological compensation coefficient.

The Pearl growth curve model formula is expressed as follows:

$$
l=\frac{L}{1+a e^{-b t}}
$$

where $l$ is a parameter representing the development characteristics of things and $L$ is the maximization of $L(L=1) ; a$ and $b$ are constants, and $t$ is time.

The inflection point of the curve is $t=\ln (a / b)$; here, $l=0.5 \mathrm{~L}$, which represents the symmetry of the inflection point of the curve. To make the model meet the demand, some conversion is necessary. According to the correspondence between the coefficient and the stage of development [31], the corresponding development stages are in the ecological compensation coefficient curve. A development stage of $1 / E n=3$ is the inflection point of the ecological compensation coefficient curve, where $E n$ is the Engel coefficient. Therefore, we used $T=t+3$ instead of the time $t$ axis as the abscissa (Figure 1).

Based on the above factors, the formula for the ecological compensation standard $\left(E_{C S}\right)$ is as follows:

$$
E_{C S}=V \cdot \alpha
$$

where $V$ is the value of the ecosystem services of water resources and $\alpha$ is The ecological compensation coefficient. 


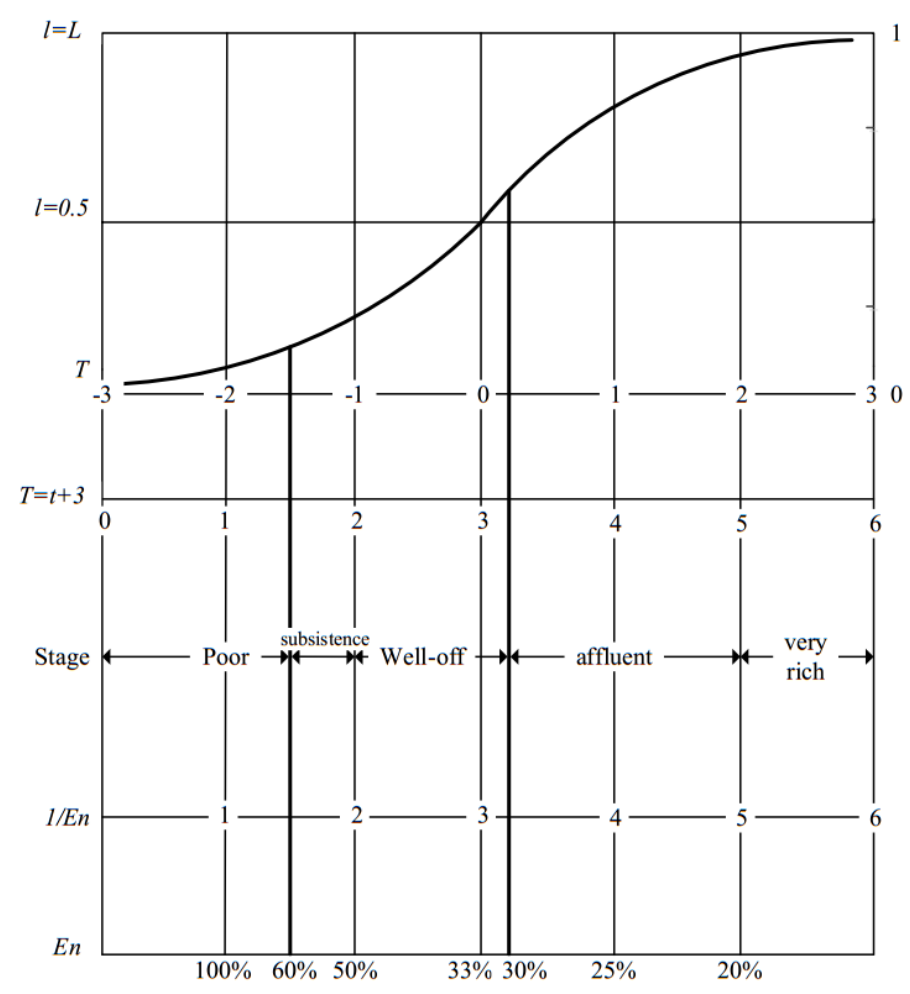

Figure 1. The Engel coefficient and the Pearl growth curve model.

\subsection{Upstream Ecological Compensation}

If there are no upstream pollution rights and the downstream pollution rights have no limits, upstream water quality should be guaranteed to meet agreement standards or national standards to achieve the corresponding watershed governance objectives. If the water quality of the section is lower than the standard or standards stipulated by the agreement, according to the "polluter pays" principle, the upstream should make a corresponding pollution compensation based on the actual water quality of the cross section [32]. Normally, major pollutants in the basin include ammonia nitrogen $\left(\mathrm{NH}_{3}\right)$, chemical oxygen demand (COD), and phosphorus (P). The compensation standard is also divided into three levels using the method to be discussed in Section 2.1. The amount of compensation for pollution in the upper reaches of the basin is less than that of the upper reaches and is set up as $E_{C P}$ as follows:

$$
E_{C P}=Q_{i} \sum_{k=1}^{l}\left[\left(H_{l}^{k}-H_{0}^{k}\right) \cdot C_{k}\right] \cdot \beta
$$

where $Q_{i}$ is the downstream exit water, $H_{l}^{k}$ is the actual determination of the downstream section of the $K$ main pollutant concentration index, and $H_{0}^{k}$ is the standard target values of the $K$ main pollutants for water bodies defined jointly between upstream and downstream. $C_{k}$ is the amount of compensation for pollutant emission units, the upstream and downstream water quality protection according to the input or the cost of the pollution control market; it can also be regarded as the water price. $\beta$ is for the implementation of pollution compensation policy according to the state and local government departments of law enforcement or an extra reward and punishment situation to determine the comprehensive consideration.

\subsection{Calculating the Shared Equity of Ecological Environments}

Upstream and downstream share the ecological rights and interests of the river basin and environmental rights [33]; following the principle of co-construction and sharing, upstream and downstream jointly conduct the ecological construction and protection of investments [34]. At the same 
time, the upstream and downstream share the basin environmental capacity under the water quality target. How should the upstream and downstream undertake their corresponding responsibilities? Most current studies have indicated that the input cost can be apportioned based on water quantity, and if there is no negotiation to reach the common goal of water quality, the injured party charges for pollution [35-37]. Therefore, in the upstream and downstream sharing of the ecological and environmental rights and interests of the river basin, the lower reaches of the river basin can consider the water and water quality indicators to determine compensation for the upstream. The amount of compensation is defined as $E_{A C}$ as follows:

$$
E_{A C}=V \cdot \alpha-Q_{i} \sum_{k=1}^{l}\left[\left(H_{1}^{k}-H_{0}^{k}\right) \cdot C_{k}\right] \cdot \beta
$$

$r_{i}$ is the comprehensive water quality index given by:

$$
r_{i}=\frac{1}{k} \sum_{j=1}^{l}\left[\left(H_{1}^{j}-H_{0}^{j}\right)\right]
$$

When the water quality is better than the standard contract (or agreement standard time), $r_{i}<0$. When the water quality is inferior to the agreed standard, $r_{i}>0$, and the upstream will compensate for the pollution because of the water quality deterioration $E_{C P}$. When the water is equal to the agreed standard, $r_{i}$ is 0 (Table 1 ).

Table 1. Ecological compensation standard based on demarcation of property right.

\begin{tabular}{cccc}
\hline Property & $\boldsymbol{r}_{\boldsymbol{i}}<\mathbf{0}$ & $\boldsymbol{r}_{\boldsymbol{i}}=\mathbf{0}$ & $\boldsymbol{r}_{\boldsymbol{i}}>\mathbf{0}$ \\
\hline Downstream ecological compensation & $V \cdot \alpha$ & $V \cdot \alpha$ & $V \cdot \alpha$ \\
Upstream ecological compensation & $E_{C P}$ & 0 & $-E_{C P}$ \\
Sharing the rights of the ecological environment & $V \cdot \alpha+E_{C P}$ & $V \cdot \alpha$ & $V \cdot \alpha-E_{C P}$ \\
\hline
\end{tabular}

\section{Case Study}

The Xiaoqing River is a provincial large-scale river in Shandong Province; its basin area accounts for approximately $1 / 15$ of the total area of the province, which is 10,336 square kilometers. The basin's economy is rapidly developing. Moreover, the Xiaoqing River is the important water lifeline of the social economy in the central region of Shandong Province. The terrain of the basin is low in the north and high in the south. Most terrain consists of hills on the south side of the Jiaoji Railway and most are depressions and plains on the north side. In the Xiaoqing River Basin, the population density is 797 inhabitants $/ \mathrm{km}^{2}$; the population density of the Xiaoqing River is 1.33 times of the average population density of Shandong province (599 inhabitants $/ \mathrm{km}^{2}$ ). The industrial and agricultural production is rapidly developing in this basin, with a per capita output value 2.23 times that of the province [38,39].

In the middle of the 1980s, based on the condition of the ecological environment in the river basin, the government of Shandong province comprehensively improved the urban environment and controlled the industrial pollution. At the same time, the government began to govern the ecological water resources in the basin, which are related to the overall socio-economic development in the province. The government compiled and implemented the comprehensive water pollution control plan for key provincial river basins such as the Xiaoqing River, Dongping Lake, Yishu River, Nansi Lake, Majia River and the Tuhai River; some coastal areas, such as Jiaozhou Bay and Laizhou Bay, were also included. Since the year 2010, the government of Shandong province has set up the river basin as an ecological compensation pilot area to comprehensively promote the ecological environmental control work in the Xiaoqing River basin. Early in 2012, the government pushed forward the establishment of a compensation mechanism in the Xiaoqing River Basin and promoted 
pollution control. The government of Shandong province has taken measures to promote ecological compensation mechanisms in both the upper and lower reaches of the river basin. Based on the integration of sewage and garbage disposal funds, ecological environmental protection funds and sewage charges, the government continued to increase its investment in environmental budget funds. In cooperation with the environmental funds allocated by the central government, the provincial finance department set up a fund of 100 million yuan to clean up the streamways of the Xiaoqing River and vigorously promote ecological and environmental management in the Xiaoqing River Basin [39].

This study defined the frontier between Jinan City and Zibo City as the boundary. The Xiaoqing River Basin of Jinan City above the city boundary is called the upstream area, and the Xiaoqing River Basin of Zibo City below the city boundary is called the lower reaches (Figure 2). Indicators, such as ecological and environmental protection investment, water allocation, compensation standards for pollutant discharge and policy enforcement, are different in each year. In this paper, we took the year 2015 as an example, during which the above indicators were relatively stable. Moreover, we used the standard model of ecological compensation in the watershed to calculate the ecological compensation limit of the basin between the upper and lower reaches of Xiaoqing River under the definition of the property rights of different ecological environments.

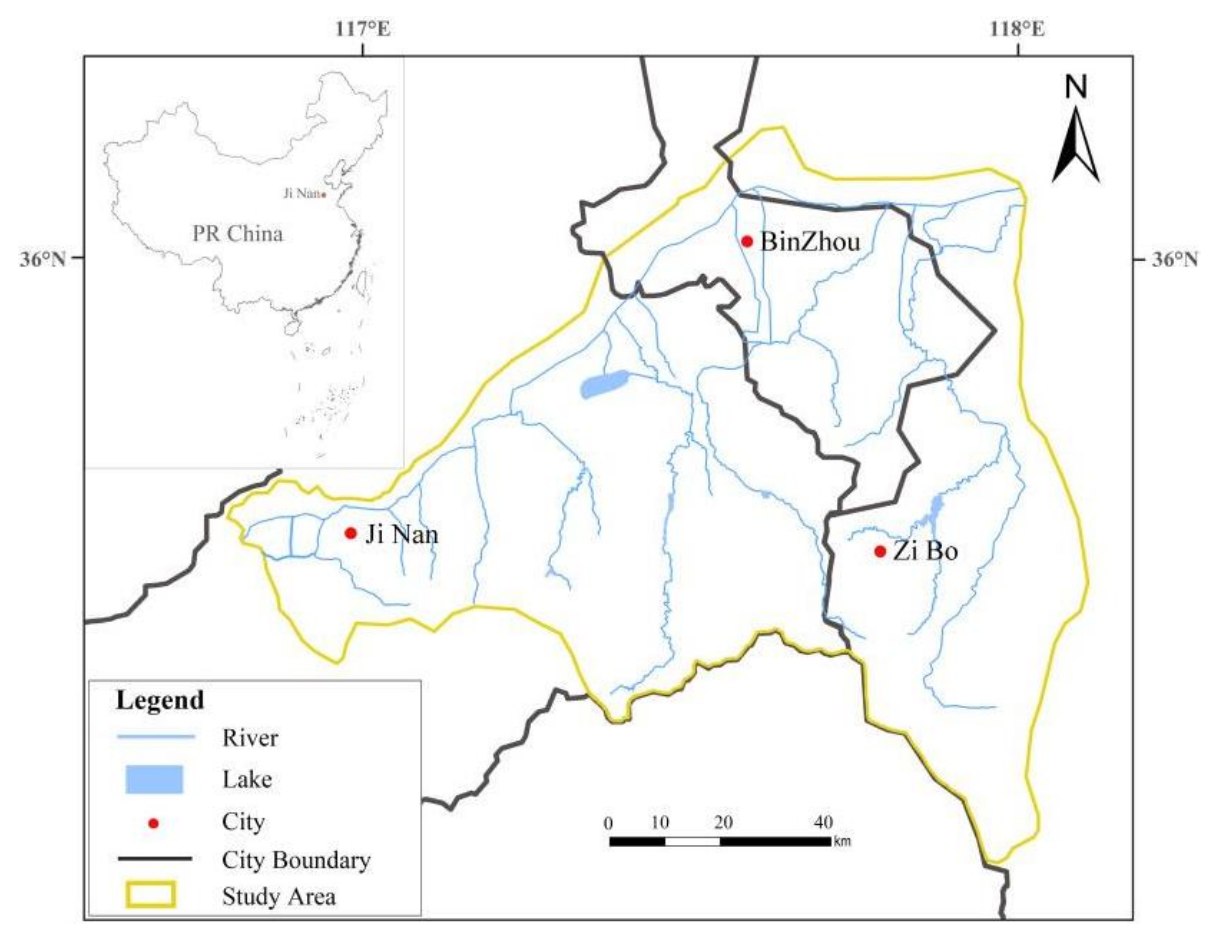

Figure 2. Location and administrative divisions of Xiaoqing River basin.

\section{Results}

\subsection{Results of Downstream Ecological Compensation}

In the case of owning the pollution rights in an upstream city, the downstream cities only need to allocate the costs of upstream urban ecological construction; the compensation includes the ecological protection of compensation, and compensation projects can be subdivided into three specific stages of the 11 kinds of specific projects. Pricing of ecological compensation in the upstream and downstream will not be unified because river water resources in different regions have their own leading ecosystem services. Therefore, ecological compensation standards of different amounts can be formulated for reference for both upstream and downstream. The ecosystem service value of water resources in 2015 of the Xiaoqing River Basin and China were calculated by using the calculation method proposed by 
Xie [25]. According to Equation (1), the water ecosystem service in the study area is divided into three stages (Table 2). As shown in the results, the eco-location quotients of water supply, gas regulation, climate regulation and hydrological regulation belong to location quotient stage one. These ecosystem service functions were classified as those in the first stage and their values totaled 3.187 billion yuan. Purifying the environment and aesthetic landscape were classified as belonging to the second stage, with a value totaling 313 million yuan and belonging to location quotient stage two in the Xiaoqing River Basin. Food production, raw material production, soil conservation, maintaining a nutrient cycle and biodiversity belonged to location quotient stage three in the Xiaoqing River Basin; they were classified as ecosystem service functions in the third stage, with a value reaching 209 million yuan.

Table 2. Ecological location quotient and division of ecosystem service functions of the Xiaoqing River.

\begin{tabular}{cccc}
\hline Ecological Compensation & Functions & Location Quotient & Stage \\
\hline \multirow{3}{*}{ Supply service } & Food production & 3.07 & 3 \\
& Raw material production & 2.45 & 3 \\
& Water resources supply & 0.65 & 1 \\
\hline \multirow{3}{*}{ Regulation service } & Gas regulation & 0.7 & 1 \\
& Climate regulation & 0.7 & 1 \\
& Purify the environment & 1.88 & 2 \\
& Hydrological regulation & 0.98 & 1 \\
\hline \multirow{2}{*}{ Support service } & Soil conservation & 2.9 & 3 \\
& Maintain a nutrient cycle & 2.45 & 3 \\
& Biodiversity & 2.77 & 3 \\
\hline Cultural service & Aesthetic landscape & 2.2 & 2 \\
\hline
\end{tabular}

The compensation standard is the core required to realize the ecological compensation of water resources and is related to the effect and affordability of compensation. The downstream needs to provide ecological compensation to the upstream if it wants to obtain the corresponding ecological service benefits through the upstream ecological construction investment because the upstream has pollution rights. The downstream should encourage the upstream to invest in ecological protection. Additionally, the proportion of the compensation for ecological protection in the upstream to the total cost should be greater than the product of its service value of water resources in the river basin and the Pearl growth curve in Equation (2).

The ecological compensation coefficient was calculated based on the Engel coefficient of the Xiaoqing River Basin. The ecological compensation coefficient $\alpha$ was calculated from Equation (3). Then, the reciprocal of the Engel coefficient was set as the horizontal axis and the ecological compensation coefficient was set as the vertical axis, as shown in Table 3. The results of the Engel coefficient for 2010-2015 show that people's living standards have reached the affluent stage from the well-off stage in which people's understanding and demands for ecological value have gradually increased with the continuous development of the social economy. Therefore, the compensation coefficient increased from 0.50 to 0.67 over the years. The results show that people's understanding and demands for the ecological value of water resources are in the intermediate stage and that the importance of ecological value for people is to meet the needs of human development among the needs of human survival, development and enjoyment.

The ecological compensation standard for water resources of the Xiaoqing River Basin were calculated from the results of the classification of water resources ecosystem services and the ecological compensation coefficients shown in Table 4. According to the principle of staged implementation, the compensation standard was divided into three stages with people's improved understanding and demands for ecological value. The ecological compensation standard formulation in the first stage was based on the ecosystem service function in the first phase, with a value of 3.187 billion yuan. According to the compensation coefficient of 0.67 based on the economic 
development level in 2015, the compensation amount for the first phase was 2.139 billion yuan. The water resource area of the Xiaoqing River Basin was $4354.6 \mathrm{~km}^{2}$ and the compensation standard was thus 0.491 million yuan $/ \mathrm{km}^{2}$. The ecological compensation standard for the second stage was based on the ecosystem service functions in the first and second stages. With a total value of 3.501 billion yuan, the total compensation amount reached 2.349 billion yuan by the compensation standard of 0.539 million yuan $/ \mathrm{km}^{2}$. Similarly, the ecological compensation standard for the third stage was based on the ecosystem service functions in the first, second and third stages. With a total value of 3.710 billion yuan, the total compensation amount reached 2.489 billion yuan by the compensation standard of 0.572 million yuan $/ \mathrm{km}^{2}$.

Table 3. Ecological compensation standard coefficients of the Xiaoqing River Basin for 2010-2015.

\begin{tabular}{ccccc}
\hline Years & Urban Engel Coefficient/\% & Rural Engel Coefficient/\% & Engel Coefficient & $\boldsymbol{\alpha}$ \\
\hline 2010 & 31.6 & 33.6 & 32.3 & 0.52 \\
2011 & 31.7 & 36.4 & 33.3 & 0.50 \\
2012 & 30.8 & 35.6 & 32.4 & 0.52 \\
2013 & 30.6 & 33.9 & 31.7 & 0.54 \\
2014 & 29.7 & 33 & 30.8 & 0.56 \\
2015 & 24.4 & 32.3 & 26.9 & 0.67 \\
\hline
\end{tabular}

Table 4. Ecological water compensation standard for the Xiaoqing River Basin for three stages.

\begin{tabular}{|c|c|c|c|}
\hline Stage & Functions & $V /$ billion yuan & $E_{C S} /$ billion yuan \\
\hline Stage one & $\begin{array}{c}\text { Water resources supply } \\
\text { Gas regulation } \\
\text { Climate regulation } \\
\text { Hydrological regulation }\end{array}$ & 3.187 & 2.139 \\
\hline Stage two & $\begin{array}{l}\text { Purify the environment } \\
\text { Aesthetic landscape }\end{array}$ & 3.501 & 2.349 \\
\hline Stage three & $\begin{array}{l}\text { Food production } \\
\text { Raw material production } \\
\text { Soil conservation } \\
\text { Maintain a nutrient cycle } \\
\text { Biodiversity }\end{array}$ & 3.710 & 2.489 \\
\hline
\end{tabular}

\subsection{Results of Upstream Ecological Compensation}

In the case of upstream pollution-free rights, the compensatory content involves only punitive compensation for pollution damage. If the upstream does not have environmental rights and the water quality cannot meet the water quality standard, the upstream needs to compensate for downstream pollution. The Class III water quality standard in the National Surface Water Standard (GB3838-2002) is generally deemed as the transboundary water quality target reflecting the current economic development and the overall level of water environments in China. At present, the number of pollutant types included in the charging range for pollutant discharge fees generally does not exceed three, and the pollution equivalents of COD, ammonia nitrogen and total phosphorus are high in the Xiaoqing River Basin. Therefore, COD, ammonia nitrogen and total phosphorus were taken as the main pollution factors in the scope of pollution compensation in this paper combined with the water quality characteristics of Jinan City and Binzhou City. By referring to the water pollution environmental protection taxing standard set by the Shandong Provincial Government, emissions charge standards of COD, ammonia nitrogen, and total phosphorus in sewage are 3000 yuan/t, 3750 yuan/t and 12,000 yuan/t, respectively.

With changing wastewater treatment costs and social development needs, emissions charge standards will change accordingly. At the same time, local governments will impose extra fines 
(or rewards) on excessive emission (or sewage emission reduction) according to the actual conditions. For example, the Management Method on Emissions Charge Standards stipulates that excessive emissions will be imposed twice as much as emission charges. Therefore, the value of $\beta$ is 2 . According to the National Surface Water Standard (GB3838-2002), the standard limits of COD, ammonia nitrogen and total phosphorus when the water quality is Class III are $20 \mathrm{mg} / \mathrm{L}, 1.0 \mathrm{mg} / \mathrm{L}$ and $0.2 \mathrm{mg} / \mathrm{L}$, respectively. Assuming that the indexes of water quality of fracture surfaces meet the limits of the various respective water quality standards, the corresponding ecological compensation amounts of the first, second and third stages according to Equation (5) are 88 million, 107 million and 124 million yuan, respectively.

\subsection{Sharing the Rights of the Ecological Environment}

When the ecological environment property relation between the upstream and downstream Xiaoqing River is to share the rights of the ecological environment, the upstream and downstream ecological protection investment and pollution compensates for comprehensive consideration and the downstream need according to the upstream ecological construction investment and water quality to produce the upstream unified ecological compensation. Shared the ecological environment rights and interests can be divided into three stages. The delimitation of property rights includes upstream having pollution right, upstream having no pollution right and sharing the rights of the ecological environment. Under the above different delimitation of property rights and the different stages, the model calculation method and the calculation formula in Table 1 were used. The ecological compensation standard between the upstream and downstream Xiaoqing River is shown in Table 5.

Table 5. Compensating standard of the downstream to the upstream of the Xiaoqing River Basin under different delimitations of property rights (100 million yuan).

\begin{tabular}{lccc}
\hline Delimitation of Property Rights/Stage & Stage One & Stage Two & Stage Three \\
\hline Downstream Ecological compensation & 21.39 & 23.49 & 24.89 \\
Upstream Ecological compensation & 0.88 & 1.07 & 1.24 \\
Sharing the rights of the ecological environment & 20.51 & 22.42 & 23.65 \\
\hline
\end{tabular}

\section{Discussion}

\subsection{Advantages of the Method}

It can be seen from the calculation results of the three kinds of ecological compensations for the Xiaoqing River Basin that ecological compensation amounts were different for different delimitations of property rights and stages. As shown in the calculation results of ecological compensation for the Xiaoqing River Basin, ecological compensations for investment had a greater impact on the total amount of ecological compensation than compensation for pollution when sharing the rights of the ecological environment. Therefore, if only one kind of ecological environment property right is taken into consideration between the upstream and downstream, other ecosystem service functions in addition to water quality provided by the ecological environment resources can be ignored, which affects the fair sharing of ecological benefits between the upstream and downstream. Whether the water quality between the upstream and downstream (interface) is better than the agreement (stipulated) standard will determine the direction of compensation between the upstream and downstream. Moreover, the water quality determines the scale of the compensation amount. Compared with the current practice of only considering the compensation for ecological protection investment or only considering compensation for water pollution, the ecological compensation standard that considers both water quality and water yield takes the goals and effects of ecological environmental protection into full consideration and considers the impacts of water quality and water yield on compensation standards. 
Moreover, the compensation content is more complete when considering the rights and interests of all parties so that it is more easily accepted by all parties.

\subsection{Deficiencies and Prospects}

In the practice of ecological compensation for the Xiaoqing River Basin, although the VAM system arrangement of water quality compensation between the upstream and downstream Xiaoqing River Basin can alleviate the interest relationship of ecological environment protection, its compensation standard lacks sufficient theoretical basis to allow the compensation for ecological protection investment to be distinguished from the punitive compensation for pollution based on different delimitations of property rights. In fact, the ecological compensation standard for the Xiaoqing River Basin only considers the indemnification for pollution based on the water quality and generally replaces the ecological compensation of the basin with indemnification for pollution; however, it neglects the corresponding compensation that should be made for the upstream ecological construction and protection investment. Its compensation content is not complete, and the compensation amount is much smaller than the upstream capital investment and profit loss, which is not conducive to coordinated social and economic development and the fair sharing of ecological environmental benefits. At the same time, the compensation for pollution based on water quality in the ecological compensation for the Xiaoqing River Basin does not have different compensation standards set for different water quality levels, and the pollution compensation standard cannot be determined according to the water quality protection investment or pollution control costs, which leads to a limited function of encouragement or restraint on ecological protection and investment jointly carried out by the upstream and downstream.

It is difficult to express the ecological benefits of water resources simply by mathematical expressions and indicators because they cover many aspects and multiple fields. After determining the final compensation standard for the study area according to the above method, we will need to verify it by actual investigation. However, the research results of this paper play a role in aiding the public to further understand the value of water ecosystem services and make people realize that the value of ecosystem services is no longer just an "astronomical figure". With the improvement of the living standards of people and the strengthened awareness of ecological environment protection, it is necessary to formulate a reasonable ecological compensation standard according to the value of ecosystem services, which needs exploration and gradual improvement. Comprehensive research methods for such a formulation need to be further explored and improved.

\section{Conclusions}

This research was based on the definition of the ecological environment from the perspective of property rights; it considered the location quotient and pollutant concentration, proposed a multi-stage standard of ecological compensation between downstream watersheds, and used the Xiaoqing River basin ecological compensation as an example to calculate the amounts of compensation and define different property and different stages under the standard. The results showed that:

(1) The standard can be divided into three cases: the upstream of the river basin ecological compensation for environmental protection through the clear definition of the ecological environment property rights of the river basin, the ecological compensation of the upper reaches and the lower reaches of the river, and the ecological rights and interests of the upper and lower reaches of the river basin. To clarify the object of ecological compensation and the content from the theory, the investment in ecological protection compensation and compensation from the Environmental Pollution Science Division were based on their integration into the ecological compensation standard and the ecological compensation standard for calculation of scientific and complete content.

(2) Compared with a fixed amount of river basin ecological compensation and considering the location quotient and concentration of pollutants of the basin, the ecological compensation multi-stage standard increases the basin ecological compensation agreement between the city space, 
and compensation becomes more comprehensive and complete and is more easily accepted by the parties.

(3) The standard will benefit the ecological environment of the watershed property of different stakeholders and will have different contents, ecological compensations and ecological compensation standards for different property rights arrangements. Additionally, the lower reaches of the basin share ecological and environmental interests; the upstream and downstream interest relationship is more fair and reasonable. Considering the interests of all parties, it should lead to more application promotion in practice.China is a developing nation in the practice of ecological compensation; how to protect the ecological environment, accelerate the improvement of ecological compensation systems, and construct ecological compensation mechanisms across the region are major reforms currently facing the country. It is necessary for us to strengthen the study of ecological compensation theory and the practice of ecological compensation in foreign countries and establish a theoretical system of ecological compensation with distinctive features to promote the practice of ecological compensation in China.

Acknowledgments: This research was funded by the Key Technology Research and Demonstration Project of Water Ecological Civilization Construction (No. 1261410110030) and the Shandong Provincial Water Conservancy Scientific Research and Technology Promotion Project (No. SDSLKY201604).

Author Contributions: This study was designed by Yuheng Yang and Shengle Cao. Xi Zhang and Leran Chang contributed to data collection and calculation. Yuheng Yang carried out calculation analysis and completed the manuscript. Xi Zhang contributed to the manuscript modification.

Conflicts of Interest: The authors declare no conflict of interest.

\section{Abbreviations}

The following abbreviations are used in this manuscript:

UNMEA the United Nations Millennium Ecosystem Assessment

NGOs Non-Governmental Organizations

WTP the willingness to pay

NDRC the National Development and Reform Commission

$\mathrm{NH}_{3} \quad$ ammonia nitrogen

COD chemical oxygen demand

P phosphorus

VAM the Valuation Adjustment Mechanism

\section{References}

1. Worthman, C.M. The Ecology of Human Development: Evolving Models for Cultural Psychology. J. Cross-Cult. Psychol. 2010, 41, 546-562, doi:10.1177/0022022110362627.

2. Shi, W. Entropy Analysis of the Coupled Human-Earth System: Implications for Sustainable Development. Sustainability 2017, 9, 1264, doi:10.3390/su9071264.

3. Finlayson, M.; Cruz, R.D.; Davidson, N.; Alder, J.; Cork, S. Millennium Ecosystem Assessment: Ecosystems and human well-being: Wetlands and water synthesis. Data Fusion Concepts Ideas 2005, 656, 87-98.

4. Fikret, B. Environmental Governance for the Anthropocene? Social-Ecological Systems, Resilience, and Collaborative Learning. Sustainability 2017, 9, 1232, doi:10.3390/su9071232.

5. Herzog, F.; Dreier, S.; Hofer, G.; Marfurtb, C.; Schupbacha, B.; Spiessb, M.; Walter, T. Effect of ecological compensation areas on floristic and breeding bird diversity in Swiss agricultural landscape. Agric. Ecosyst. Environ. 2005, 108, 189-204, doi:10.1016/j.agee.2005.02.003.

6. Yin, R.; Zhao, M. Ecological restoration programs and payments for ecosystem services as integrated biophysical and socioeconomic processes-China's experience as an example. Ecol. Econ. 2012, 73, 56-65, doi:10.3390/su907123.

7. Yin, R.S.; Zhao, M.J. Estimation of Ecological Compensation Standards for Fallow Heavy Metal-Polluted Farmland in China Based on Farmer Willingness to Accept. Ecol. Econ. 2012, 73, 56-65, doi:10.1016/j.ecolecon.2011.11.003. 
8. Wunder, S. Payments for Environmental Services: Some Nuts and Bolts; CIFOR Occasional Paper; Center for International Forestry Research: Jakarta, Indonesia, 2005; Volume 42, p. 24.

9. Qiu, L.; Zhai, H.J. An Ecological Compensation Mechanism of Chishui River Water Resources Protection and Research. Appl. Mech. Mater. 2014, 685, 463-467, doi:10.4028/www.scientific.net/AMM.685.463.

10. Zhang, H.; Liu, G.; Wang, J.; Wan, J. Policy and Practice Progress of Watershed Eco-compensation in China. Chin. Geogr. Sci. 2007, 17, 179-185, doi:10.1007/s11769-007-0179-6.

11. Chen, S.; Zhang, Z.H.; Ma, Y.; Shi, H.H.; Ma, A.Q. Program for service evaluation of marine ecosystems in China waters. Adv. Earth Sci. 2006, 21, 1127-1133. (In Chinese)

12. Pagiola, S.; Arcenas, A.; Platais, G. Can Payments for Environmental Services Help Reduce Poverty? An Exploration of the Issues and the Evidence to Date from Latin America. World Dev. 2005, 33, 237-253, doi:10.1016/j.worlddev.2004.07.011.

13. Pimentel, D.; Wilson, C.; Mccullum, C.; Huang, R.; Dwen, P. Economic and environmental benefits of biodiversity. Bioscience 1997, 47, 747-757, doi:10.2307/1313097.

14. Kong, F.; Xiong, K.; Zhang, N. Determinants of Farmers' Willingness to Pay and Its Level for Ecological Compensation of Poyang Lake Wetland, China: A Household-Level Survey. Sustainability 2014, 6, 6714-6728, doi:10.3390/su6106714.

15. Qin, Y.H.; Kang, M.Y. A Review of Ecological Compensation and Its Improvement Measures. J. Nat. Resour. 2007, 22, 557-567. (In Chinese)

16. Yu, G.; Liu, D.; Liao, X.; Wang, T.; Tian, Q.J.; Liao, Y. Quantitative Research on Regional Ecological Compensation from the Perspective of Carbon-Neutral: The Case of Hunan Province, China. Sustainability 2017, 9, 1095, doi:10.3390/su907109.

17. Chen, W.; Bai, Y.; Zhang, W.; Lyu, S.D.; Jiao, W.T. Perceptions of Different Stakeholders on Reclaimed Water Reuse: The Case of Beijing, China. Sustainability 2015, 7, 9696-9710, doi:10.3390/su7079696.

18. Hao, C.X.; Wen, Y.L. Game Analysis on Benefit of Chinese Wetland Ecological Compensation. Adv. Mater. Res. 2012, 518-523, 4835-4838, doi:10.4028/www.scientific.net/AMR.518-523.4835.

19. Liu, C.X. Analysis on the Ecological Compensation in China's Water Source Protection Zones: A Case Study of the Middle Route Water Source Area of the South-to-North Water Transfer Project. Adv. Mater. Res. 2012, 524-527, 3005-3020, doi:10.4028/www.scientific.net/AMR.524-527.3005.

20. Wang, L.J. The latest progress of eco-compensation in China. In Proceedings of the 2011 International Conference on E-Business and E-Government, Shanghai, China, 6-8 May 2011.

21. Party, C.C. The Report of the 18th CPC Central Committee to the General Assembly was Made by Comrade Xi Jinping. Available online: http://cpc.people.com.cn/19th/n1/2017/1019/c414305-29595277.html (accessed on 19 October 2017).

22. Engel, S.; Pagiola, S.; Wunder, S. Designing payments for environmental services in theory and practice: An overview of the issues. Ecol. Econ. 2008, 65, 663-674, doi:10.1016/j.ecolecon.2008.03.011.

23. Schomers, S.; Matzdorf, B. Payments for ecosystem services: A review and comparison of developing and industrialized countries. Ecosyst. Serv. 2013, 6, 16-30, doi:10.1016/j.ecoser.2013.01.002.

24. Ma, Y.X.; Wang, J.L.; Wang, J. Study on Ecological Compensation Standard in River Basin Based on the Property Rights of Eco-environment. J. Nat. Resour. 2017, 32, 1325-1336, doi:10.11849/zrzyxb.20160784. (In Chinese)

25. Xie, G.; Li, W.H.; Xiao, Y.; Zhang, B.A.; Lu, C.X. Forest Ecosystem Services and Their Values in Beijing. Chin. Geogr. Sci. 2010, 20, 51-58, doi:10.1007/s11769-010-0051-y.

26. Pei, S.; Xie, G.; Liu, C.; Zhang, C.S.; Li, S.M.; Chen, L. Dynamic Changes of Water Conservation Service of Typical Ecosystems in China within a Year Based on Data from CERN. Sustainability 2015, 7, 16513-16531, doi:10.3390/su7121582.

27. Lee, Y.J.; Tung, C.M.; Lee, P.R.; Lin, S.H. Personal Water Footprint in Taiwan: A Case Study of Yunlin County. Sustainability 2016, 8, 1112, doi:10.3390/su8111112.

28. Li, F.; Li, W.H.; Zhen, L.; Huang, H.Q.; Wei, Y.J.; Naomi, I. Estimating Eco-compensation Requirements for Forest Ecosystem Conservation-A Case Study in Hainan province, southern China. Outlook Agric. 2011, 40, 51-57, doi:10.5367/oa.2011.0028.

29. Matis, J.H.; Kiffe, T.R.; Werf, W.V.D.; Costamagnad, A.C.; Matise, T.I. Population dynamics models based on cumulative density dependent feedback: A link to the logistic growth curve and a test for symmetry using aphid data. Ecol. Model. 2009, 220, 1745-1751, doi:10.1016/j.ecolmodel.2009.04.026. 
30. Li, J.C. New Theory of Resource Economy; Chongqing University Press: Chongqing, China, 1995.

31. Wunder, S. When payments for environmental services will work for conservation. Conserv. Lett. 2013, 6, 230-237, doi:10.1111/conl.12034

32. Dong, Z.; Yan, Y.; Duan, X.; Fu, X.; Zhou, Q.R. Computing payment for ecosystem services in watersheds: An analysis of the Middle Route Project of South-to-North Water Diversion in China. J. Environ. Sci. 2011, 23, 2005-2012, doi:10.1016/S1001-0742(10)60663-8.

33. Song, B.; Zhang, X.; Xin, Y.L.; Xue, L.L. Notice of Retraction Ecological Compensation Accounting for Provinces in China Based on Modification from Ecological Resources Conversion Efficiency and Payment Willingness. In Proceedings of the International Conference on E-Business and E-Government (ICEE 2010), Guangzhou, China, 7-9 May 2010; pp. 3932-3937.

34. The Xinhua News Agency. The CPC Central Committee's Proposal to Formulate the 13th Five-Year Plan for National Economic and Social Development. Available online: http:/ /www.gov.cn/xinwen/2015-11/03/ content_5004093.htm (accessed on 3 November 2015).

35. Ferraro, P.J. Asymmetric Information and Contract Design for Payments for Environmental Services. Ecol. Econ. 2008, 65, 810-821, doi:10.1016/j.ecolecon.2007.07.029.

36. Vatn, A. An Institutional Analysis of Payments for Environmental Services. Ecol. Econ. 2010, 69, 1245-1252, doi:10.1016/j.ecolecon.2009.11.018.

37. Hecken, G.V.; Bastiaensen, J. Payments for Ecosystem Services: Justified or Not A Political View. Environ. Sci. Policy 2010, 13, 785-792, doi:10.1016/j.envsci.2010.09.006.

38. Xiaoqing River Management Office. Overview of Xiaoqing River. Available online: http:/ /www.xqh.org.cn/ 2012/1219/120.html (accessed on 19 December 2012).

39. Xu, Y.; Li, W.; Ding, X.W. A stochastic multi-objective chance-constrained programming model for water supply management in Xiaoqing River watershed. Water 2017, 9, 378, doi:10.3390/w9060378.

(C) 2018 by the authors. Licensee MDPI, Basel, Switzerland. This article is an open access article distributed under the terms and conditions of the Creative Commons Attribution (CC BY) license (http:/ / creativecommons.org/licenses/by/4.0/). 